\title{
Current Strategies for the Management of Anomalous Origin of Coronary Arteries from the Pulmonary Artery
}

\author{
Metin Onur Beyaz, ${ }^{1}$ Senay Coban, ${ }^{2}$ Mustafa Ozer Ulukan, ${ }^{1}$ Mehmet Sait Dogan, ${ }^{3}$ Cengiz Erol, ${ }^{3}$ \\ Turkay Saritas, ${ }^{2}$ Abdullah Erdem, ${ }^{2}$ Celal Akdeniz, ${ }^{2}$ Murat Ugurlucan, ${ }^{1}$ Atif Akcevin, ${ }^{3}$ Halil Turkoglu ${ }^{1}$ \\ ${ }^{1}$ Department of Cardiovascular Surgery, Istanbul Medipol University Faculty of Medicine; ${ }^{2}$ Department of Pediatric \\ Cardiology, Istanbul Medipol University Faculty of Medicine; ${ }^{3}$ Department of Cardiovascular Surgery, Istanbul Medipol \\ University Faculty of Medicine
}

\section{ABSTRACT}

Introduction: The coronary arteries, which have to originate from the aorta, may sometimes rise from the pulmonary artery. This study evaluated clinical and diagnostic findings, treatment methods, and follow up of cases with anomalous coronary arteries arising from the pulmonary artery.

Patients and methods: Eight patients with the diagnosis of anomalous left coronary artery from the pulmonary artery (ALCAPA) $(\mathrm{N}=6)$ and anomalous right coronary artery from the pulmonary artery (ARCAPA) $(\mathrm{N}=2)$, between January 2014 and January 2020 from a single center university hospital, were included in the study. Data from patients' demographic characteristics, electrocardiography, echocardiography, angiographic findings, operation, hospitalization, and follow up were evaluated.

Results: The study included eight patients (six females and two males) - six patients with ALCAPA and two with ARCAPA. The ages of the patients ranged between 3-135 (average: 53.25) months. The median body weight was calculated as $17.4 \mathrm{~kg}$. Severe mitral valve insufficiency was detected in two patients and two other patients had a moderate degree of mitral insufficiency on echocardiography. Ejection fractions ranged between $16-74 \%$. One patient had perimembranous malalignment large ventricular septal defect with pulmonary stenosis. Operative techniques were Takeuchi procedure (three patients), direct implantation (four patients), and left internal thoracic artery to left main coronary artery bypass (one patient). Mechanical cardiac support was not required in the postoperative period. Mortality did not occur. Mitral insufficiency and ejection fractions improved following correction of the coronary anatomy.

Conclusion: It is important to diagnose the ALCAPA or ARCAPA, where the coronary artery originates from the

Received October 24, 2020; received in revised form November 18, 2020; accepted November 18, 2020.

Correspondence: Prof. Dr. Halil Turkoglu, Istanbul Medipol University Faculty of Medicine, Medipol Mega University Hospital, TEM Avrupa Otoyolu Goztepe Cikisi, No:1, 34214 Bagcilar, Istanbul, Turkey; +90-532-32178-10; fax: +90-212-521-23-77 (e-mail: halil.turkoglu@medipol.com.tr, metinonurbeyaz@gmail.com,muratugurlucan@yahoo.com). pulmonary artery. Patients should be treated before congestive heart failure and fatal complications occur. Surgical correction should be planned regardless of symptom status, even though some of patients reach adulthood with an increased number of collaterals.

\section{INTRODUCTION}

The coronary arteries, which have to originate from the aorta, may sometimes rise from the pulmonary artery. Four different variations have been reported for coronary arteries originating from the pulmonary artery. The most common type is ALCAPA, which is defined as the origin of the left coronary artery from the pulmonary artery, and more rarely, ARCAPA, which is defined as the origin of the right

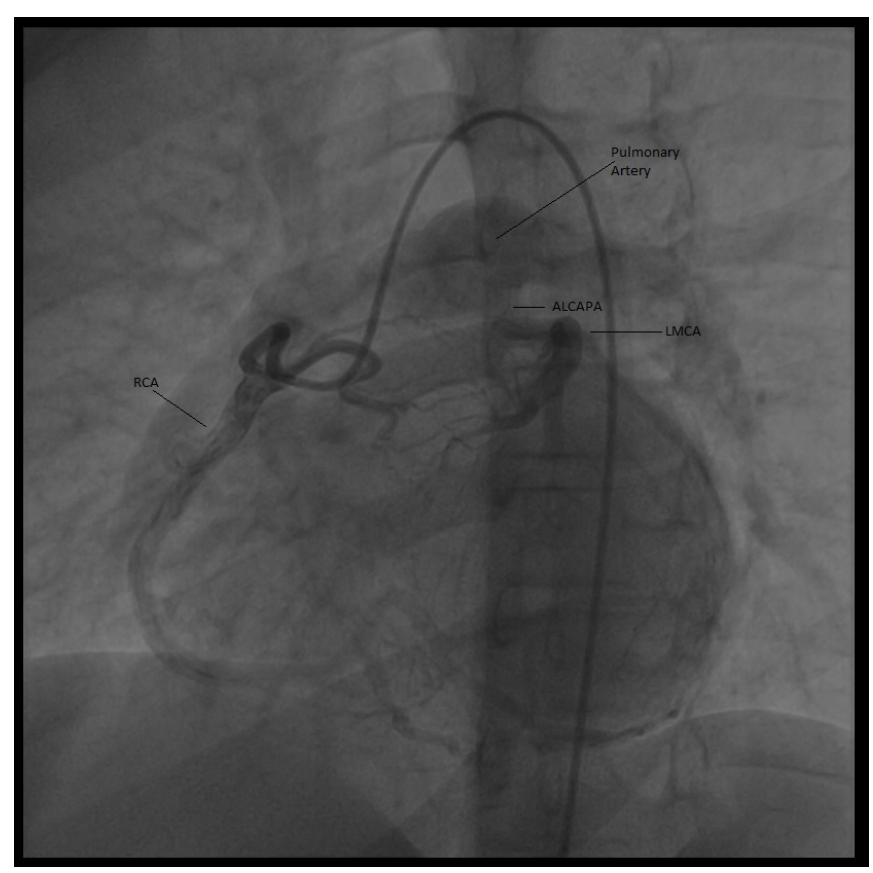

Figure 1. Coronary angiography image of anomalous left coronary artery from the pulmonary artery. Image shows the left coronary artery retrograde filling when the contrast is injected from the right coronary ostium. 
Table 1. Demographic and preoperative features of the patients

\begin{tabular}{|c|c|c|c|c|}
\hline $110 \mathrm{M}$ & $\mathrm{F}$ & $28 \mathrm{~kg}, 133 \mathrm{~cm}$ & ARCAPA, EF 60\%, MVI none, LVEDd $41 \mathrm{~mm}$, Z score (0.74), PH none & Regular \\
\hline $37 M$ & $\mathrm{~F}$ & $13 \mathrm{~kg}, 92 \mathrm{~cm}$ & ALCAPA, EF 55\%, MVI none, LVEDd $39 \mathrm{~mm}, \mathrm{Z}$ score (3), PH mild & Regular \\
\hline $50 M$ & $\mathrm{~F}$ & $15 \mathrm{~kg}, 100 \mathrm{~cm}$ & ALCAPA, EF 50\%, MVI severe, LVEDd $41 \mathrm{~mm}$, Z score (3.3), PH none & Regular \\
\hline $64 M$ & $\mathrm{~F}$ & $21 \mathrm{~kg}, 112 \mathrm{~cm}$ & ALCAPA, EF $63 \%$, Severe MVI, LVEDd $44 \mathrm{~mm}$, Z score (2.65), PH none & Regular \\
\hline $135 \mathrm{M}$ & $\mathrm{F}$ & $38 \mathrm{~kg}, 145 \mathrm{~cm}$ & ALCAPA, EF 74\%, Mid MVI, LVEDd $40 \mathrm{~mm}$, Z score (0.55), PH none & D1 aVL, V1-4 T negative \\
\hline $15 \mathrm{M}$ & M & $10 \mathrm{~kg}, 66 \mathrm{~cm}$ & ARCAPA, EF 66\%, MVI none, LVEDd $31 \mathrm{~mm}, \mathrm{Z}$ score 4.11, PH none & Regular \\
\hline
\end{tabular}

ALCAPA, anomalous left coronary artery from the pulmonary artery; ARCAPA, anomalous right coronary artery from the pulmonary artery; F, female; M, male; kg, kilogram; cm, centimeter, EF, ejection fraction; DCMP, dilated cardiomyopathy; LVEDd, left ventricular end diastolic diameter; MVI, mitral valve Insufficiency; VSD, ventricular septal defect; ECG, electrocardiography; $\mathrm{PH}$, pulmonary hypertension

coronary artery from the pulmonary artery. Less common than ALCAPA and ARCAPA are the cases that accessory coronary arteries and all coronary blood supply originate from the pulmonary artery [Koestenberger 2007].

ALCAPA was first described in 1933. It occurs quite rarely and forms 1/200 of all congenital heart anomalies. Although it is more common in males, it is seen with an average frequency of 1/300000 [Friedman 2010]. Myocardial infarction during the course of ALCAPA may result in heart failure and sudden death [Sato 2013]. It occurs in the first 6 months of life with a decrease in pulmonary vascular resistance and associated decrease in coronary artery flow. In cases where coronary artery collaterals develop well, patients may be asymptomatic until adulthood. The mortality of ALCAPA is quite high, and $90 \%$ of untreated cases die within the first year of life due to congestive heart failure and dilated cardiomyopathy [Kristensen 2008]. ARCAPA has a prevalence of $1 / 500$ and often can remain asymptomatic. It is more difficult to gauge the true prevalence of cases with isolated ARCAPA, as diagnosis is difficult due to the lack of symptoms. Patients with isolated ARCAPA are incidentally diagnosed with angiography that is performed for other reasons [Guenther 2020].

Surgical correction is strongly recommended even if the patient is asymptomatic. Patients diagnosed with ALCAPA carry a risk of coronary ischemia, heart failure, and sudden cardiac death [Zheng 2010]. Patients with associated cardiac anomalies are diagnosed early in life, when compared with the patients with isolated ARCAPA. Those without associated cardiac defects may present with a heart murmur, congestive symptoms, and sudden cardiac death or may remain asymptomatic. Detection of ARCAPA, during coronary angiography evaluation, generally is random for other problems, such as chest pain [Gupta 2012]. Normally, there is a retrograde flow in the anomalous artery, due to the pressure difference between systemic and pulmonary circulation leading to intercoronary steal phenomena. Any increase in oxygen demand leads to depletion of the physiological reserve that causes ischemia, infarction, and sudden cardiac arrest [Parasramka 2011]. Sudden cardiac death occurs due to the right coronary artery originating from the pulmonary trunk, and therefore a corrective operation is recommended regardless of the symptom condition [Balakrishna 2017]. The most preferred surgical strategies are Takeuchi operation (intrapulmonary compartment) and direct re-implantation of the left main coronary artery (LMCA) onto the aortic root [Ceylan 2013]. Bypass with the internal thoracic arteries may be preferred for patients who can reach adulthood.

In this report, we present our experiences with anomalous coronary arteries originating from the pulmonary artery.

\section{PATIENTS AND METHODS}

Eight patients with the diagnosis of ALCAPA $(\mathrm{N}=6)$ and ARCAPA $(\mathrm{N}=2)$, between January 2014 and January 2020 in a single center university hospital, were included in the study (Figure 1). The patients were investigated retrospectively. Before the procedure, the entire coronary anatomy and cardiac structures were examined in detail with echocardiography (ECHO), cardiac catheterization, and/or cardiac computerized tomography angiography. Patients with anomalous coronary arteries were evaluated with electrocardiography for pathological Q waves at D1, AVL, and V4-V6 and the presence of an inverted $\mathrm{T}$ wave. Symptoms of the patients included fatigue, exercise intolerance, and sweating. Feeding difficulties were observed in the early infancy period.

All patients underwent surgical treatment. The preferred surgical techniques were: Takeuchi procedure for patients during the infancy period or when the coronary artery arising from the pulmonary artery was remoted from the aorta; direct implantation technique, if possible; or a bypass using the internal thoracic artery. The surgical technique involving the use of the saphenous vein between the left anterior descending artery and the aorta was not preferred due 

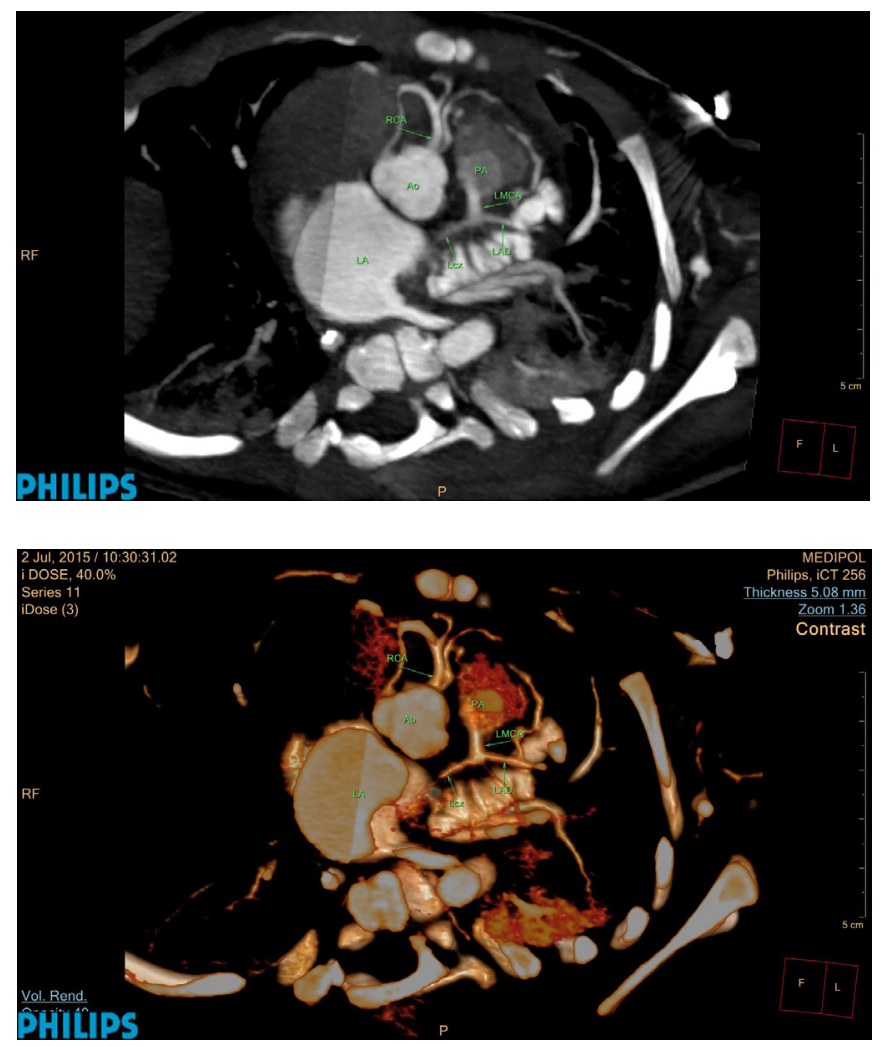

Figure 2. A, and B, Computerized tomography angiography of a patient with ALCAPA.

to need for reoperation secondary to intimal hyperplasia or atherosclerosis.

Statistical analysis: Statistical analysis was not performed due to the small sample size. Discrete data were expressed in frequencies and percentages. Continuous variables were expressed as mean \pm SD and as counts for categorical variables. Analysis of the data and calculations were performed using SPSS 18.0 (Package for Social Sciences Inc., Chicago, IL, US) computer software.

\section{RESULTS}

Clinical findings: Six ALCAPA and two ARCAPA cases were included in the study. There was one boy and five girls in the ALCAPA group. The ARCAPA group included one boy and one girl. The ages of the patients ranged between 3-135 (average: 53.25) months. The median body weight was calculated as 17.4 (average: 6-38) $\mathrm{kg}$.

While four of six patients with ALCAPA had varying degrees of left ventricular dilatation and dysfunction, one patient had dilated cardiomyopathy with an ejection fraction $(\mathrm{EF})$ of $16 \%$ at the preoperative ECHO. The mean preoperative $\mathrm{EF}$ was $52.38 \pm 6.63 \%$ (median: $57.5 \%$, range: $16-74 \%)$. There was mild pulmonary hypertension in one patient. The mean preoperative left ventricular end diastolic diameter and $Z$ scores were $40.6 \pm 1.63$ (median: $41 \mathrm{~mm}$,

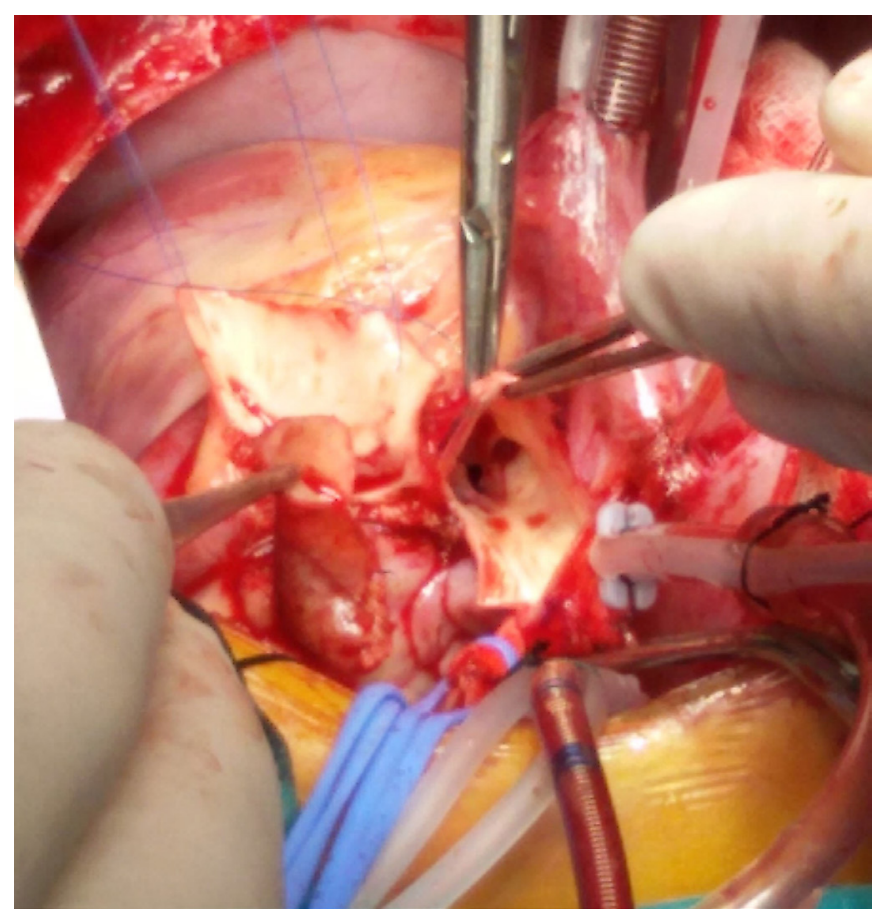

Figure 3. Takeuchi procedure, the pericardial tunnel prepared for the left coronary artery.

range: $38-47 \mathrm{~mm}$ ) and $4.07 \pm 1.31$ (median: 3.15 , range: 0.55 12.2), respectively.

Severe mitral valve insufficiency was detected in two patients and two other patients had a moderate degree of mitral insufficiency on ECHO. One patient had perimembranous malalignment large ventricular septal defect with pulmonary stenosis (gradient: $90 \mathrm{mmHg}$ ). There was negative $\mathrm{T}$ waves on the electrocardiograms of two patients at the leads D1, aVL, and V1-4. Coronary angiography was performed in four cases (Figure 1). Computerized tomography angiography was performed in four cases (Figures 2A and $2 \mathrm{~B}$ ).

The demographic feaures and preoperative findings of the patients are presented on Table 1.

Surgical treatment: Operative techniques were Takeuchi procedure (Figure 3) in three cases, including the vetricular septal defect closure and right ventricular outflow tract reconstruction in one, direct implantation (Figure 4) of two ALCAPAs and two ARCAPAs and left internal thoracic artery to left main coronary artery bypass (Figure 5) [Ata 2019], in one case. Mean cross-clamp and cardiopulmonary bypass times were $99.75 \pm 9.43$ minutes (median: 100.5 , range: $62-142$ minutes) and $139.88 \pm$ minutes (median 134.5, range: 85-181 minutes). Mitral insufficiency did not interfere in any of the patients.

Follow up: The follow-up periods were divided into early, medium, and long-term. The early period included the operative and postoperative course until discharge from the hospital. Midterm follow up was accepted as the first 1-month period, and long-term follow up was accepted beyond the first 6 months. The patients were followed up a mean of 


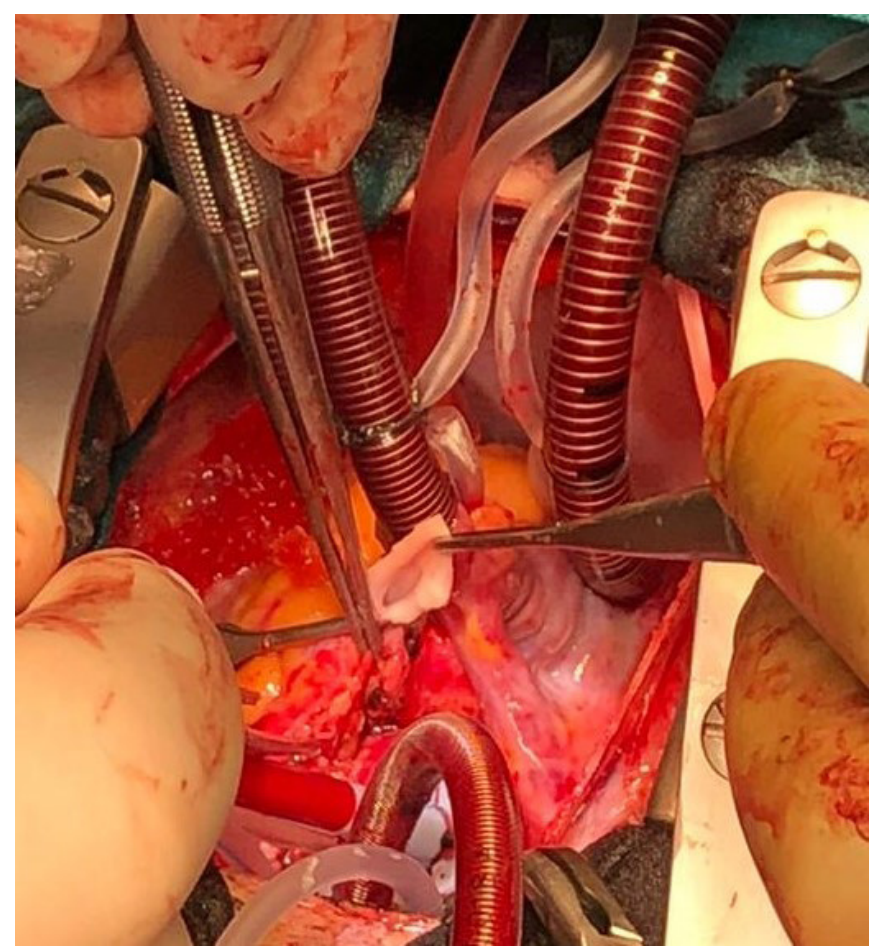

Figure 4. Coronary artery ostium prepared for direct implantation.

$44.75 \pm 8.65$ (median: 39.5 range: $7-79$ ) months. Mortality did not occur.

All patients were transferred to the pediatric section of the intensive care unit of cardiovascular surgery, while still intubated on mechanical ventilation. Mean duration of mechanical ventilation was $13.88 \pm 1.77$ hours (median: 12 , range: 8-24 hours). Patients were discharged from the intensive care unit at a mean $36.75 \pm 7.42$ hours (median: 36 , range $14-84$ hours), and mean length of hospital stay was $10.25 \pm 3.16$ days (median 5.5, range: 5-29 days). The patient with ventricular septal defect and pulmonary stenosis, who underwent complete repair, was readmitted to the intensive care unit due to food aspiration at the ward follow up on the fifth postoperative day. The patient was intubated and followed on mechanical ventilation for 27 days. A tracheostomy was executed for the patient, and she was discharged home with neurologic sequela after 29 days with tracheostomy and home ventilator support.

The main reasons of mortality in this particular patient population are low cardiac output and ventricular arrhythmias. Advanced life-support systems to reduce mortality are proposed in the literature to prevent mortality [Jian-Yong 2010]. Postoperative left ventricular functions were not worse than preoperative measurements in our patients; therefore, extracorporeal membrane oxygenation (ECMO) support was not required in our cases. Although ECMO was readily available for the patient with severely decompressed systolic dysfunction (EF:16\%), it was not required as the patient could be weaned off cardiopulmonary bypass easily and successfully.

Early ECHO controls showed improved mitral valve insufficiency. The mean EF was measured at $58.6 \pm 2.83 \%$ (median:

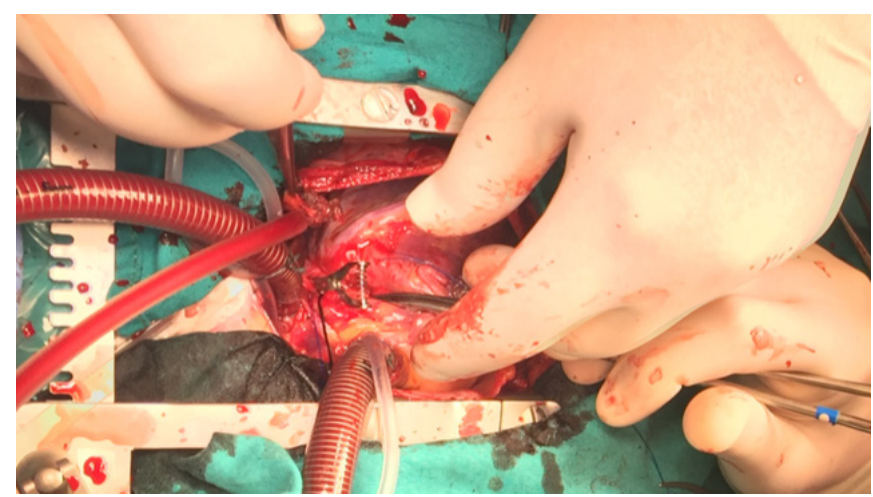

Figure 5. Bypass with the left internal thoracic artery.

$60 \%$, range: $50-70 \%)$. The EF of ALCAPA case with dilated cardiomyopathy increased to $50 \%$ in the first month control ECHO.

In the long run, trivial mitral regurgitation was observed at the 6th month ECHO control of only one patient. The left ventricular systolic functions recovered in all with a mean EF of $69.1 \pm 2.31 \%$ (median: $68.5 \%$, range: $60-81 \%$ ). All patients were followed up with no symptoms, active, and within normal limits of growth. The patient sent home with a tracheostomy cannula and home ventilator was weaned off the mechanical ventilator and the tracheostomy cannula at the 13 th month. Although she improved, she still receives physiotherapy.

Heparinization routinely was administered in the postoperative period of all patients. Standard heparin at 100 unit/ $\mathrm{kg}$ was prescribed in the first two days of the operation. After two days, the patients received $0.5 \mathrm{mg} / \mathrm{kg} / \mathrm{dose}$ lowmolecular-weight heparin twice daily. At discharge, $5 \mathrm{mg} / \mathrm{kg}$ acetylsalycylic acid was given to the patients.

Operative characteristics of the patients, operation techniques, and follow-up ECHO features are presented on Table 2.

\section{DIscussioN}

The pulmonary artery and aortic pressures are similar during fetal life. The symptoms of patients with abnormal coronary originating from the pulmonary artery start after birth, with decreasing pulmonary vascular resistance. Hence, early after birth, retrograde flows toward the pulmonary artery affects the physiologic coronary blood flow. Secondary coronary steal signs and symptoms of coronary ischemia may occur [Matherne 2008]. Depending on the symptoms, such as congestive heart failure, diagnosis is possible in the first year of life when investigating the baby for irritability, fatigue, inability to feed, sweating, and tachypnea. In rare cases where coronary collaterals develop well [Conkbayir 2019], patients may grow asymptomatic; however, these patients may experience sudden death in adulthood [Jian-Yong 2010]. In cases that cannot be diagnosed, any increase in oxygen demand in the early infantile period causes depletion of the physiological reserve and this causes myocardial infarction, leading to ischemia or sudden cardiac arrest [Guzeltas 2017]. Subendocardial infarcts and ischemia of papillary muscles due 
Table 2. Operative characteristics of the patients, the operative techniques, follow-up echocardiography results at the 1st and 6th months.

\begin{tabular}{|c|c|c|c|c|c|c|c|}
\hline ALCAPA, DCMP, Mid MVI & Direct implantation & $165 \mathrm{~min}$ & $100 \mathrm{~min}$ & 17 hours & 19 days & EF 50\%, Mid MVI & EF $81 \%$, Minimal MVI \\
\hline ALCAPA, VSD, PS & Takeuchi procedure & $174 \mathrm{~min}$ & $124 \mathrm{~min}$ & 16 hours & 29 days & EF $50 \%$, Min MVI & EF $67 \%$, MVI None \\
\hline ALCAPA, Severe MVI & Takeuchi procedure & $181 \mathrm{~min}$ & $142 \mathrm{~min}$ & 10 hours & 5 days & EF 61\%, Min MVI, MVP & EF 65\%, MVP \\
\hline ALCAPA, Mid MVI & LIMA-LMCA bypass & $132 \mathrm{~min}$ & $110 \min$ & 12 hours & 5 days & EF 70\%, Min MVI & EF $70 \%$, MVI None \\
\hline ARCAPA & Direct implantation & $120 \mathrm{~min}$ & $101 \mathrm{~min}$ & 24 hours & 8 days & EF 68\%, MVI None & EF 75\%, MVI None \\
\hline
\end{tabular}

ALCAPA, anomalous left coronary artery from the pulmonary artery; ARCAPA, anomalous right coronary artery from the pulmonary artery; CBP, cardiopulmonary bypas; MV time, mechanical ventilation time; EF, ejection fraction; MVI, mitral valve insufficiency; AR, aortic regurgitation

to coronary ischemia may cause mitral valve insufficiency. It has been shown that the establishment of physiological coronary circulation without mitral valve repair leads to improved left ventricular functions, regardless of age at the time of repair and mitral regurgitation decreases over time in surviving patients [Yakut 2019; Georgiev 2012]. Our clinical experience provides an idea that mitral valve insufficiency caused by subendorcardial ischemia resolves in a short period of time postoperatively. When our patients were evaluated preoperatively with $\mathrm{ECHO}$, we detected the consequences of chronic ischemia. Four of six patients with ALCAPA had varying degrees of left ventricular dilation and dysfunction. One of these patients already had developed dilated cardiomypathy, and the EF was measured as $16 \%$. Severe mitral valve insufficiency was detected in two patients; moderate mitral valve insufficiency was detected in another two patients. We observed striking improvement in mitral valve leak rates in all patients with mitral regurgitation even at the 1st month ECHO controls. Minimal mitral valve insufficiency was detected in only one patient on the postoperative 6th month ECHO. Left ventricular systolic functions returned to normal in all patients. Patients were followed up with no symptoms, active, and normal growth.

Although the coronary arteries originating from the pulmonary artery is usually an isolated anomaly, the most common cardiac defects are reported to be ALCAPA, ARCAPA, tetralogy of Fallot, and aortopulmonary window. Other relatively less common congenital cardiac disorders include aortic stenosis, septal defects, and aortic coarctation [Su 2007]. In our series, one patient had perimembranous malalignment ventricular septal defect and infundibular pulmonary stenosis accompanying the ALCAPA.

Cardiomegaly can be seen on the chest X-rays of patients with ALCAPA and ARCAPA. Electrocardiography may be normal in ALCAPA or signs of anterolateral ischemia/infarction may occur in leads D1, AVL and V4-V6. Pathological Q waves and reverse T waves can be seen in ARCAPA [Ceylan 2013]. Non-specific electrocardiography changes can be seen in patients with well developed coronary collaterals [Zheng 2010]. In all cases with non-specific electrocardiography changes, the possibility of coronary artery anomalies should also be considered. $T$ wave negativities were observed in D1 and $\mathrm{aVL}$ and V1-V4 in two patients in our study.

Abnormal origin of the coronary artery, enlargement of the left heart structures, decrease in systolic functions and mitral regurgitation and aneurysmatic expansion of the coronary artery can be diagnosed with echocardiography. In addition, diastolic retrograde flow from the coronary artery to the pulmonary artery can be observed by doppler evaluation [Ghaderi 2014]. Cardiac computerized tomography, coronary angiogram, and cardiovascular magnetic resonance imaging provide detailed anatomical information about the origin, course and relationship of the abnormal coronary artery with other myocardial and cardiovascular structures [Pandey 2019].

Oxygen, diuretics, afterload-reducing agents, and inotropic support are used for the treatment of congestive heart failure. With oxygen and drugs that reduce after-load, pulmonary arterial pressure may decrease, which may increase coronary retrograde flow and coronary ischemia findings in cases of ALCAPA/ARCAPA pathologies. Medical management of the patients with ALCAPA is challenging [Bonnemains 2010]. When patients with abnormal origin coronary artery are not treated surgically, the pathology results in chronic myocardial ischemia and sudden death may occur. Hence, it is recommended to plan surgical treatment as soon as the condition is diagnosed [Li 2020].

Various surgical techniques are explained for the treatment of the pathology. The surgical ligation of the left coronary artery with an aim to prevent coronary steal has historical value, but is no longer used because of its high mortality rates [Williams 2006]. The goals of surgical correction are to eliminate the shunt from left to right and to ensure double 
coronary circulation. This prevents the potential risk of myocardial ischemia caused by coronary steal phenomenon [Alexi-Meskishvili 2011]. On the other hand, myocardial protection during surgical treatment has utmost importance [Ugurlucan 2020].

The technique known as Takeuchi procedure is usually executed in early childhood, where the flow between ostium and aorta is provided by using an intrapulmonary tunnel. Takeuchi procedure is the preferred technique when the distance between the empty left aortic sinus and location of the origin of the anomalous left coronary artery are not suitable for button type anastomosis [Tsutsumi 2014]. It was preferred in three of our cases in whom direct implantation of the ALCAPA were found presumably challenging. Complication rates, such as pulmonary artery stenosis and the need for reoperation following the procedure, are common with this technique [Ata 2019]. The most commonly used technique is the direct implantation technique of the abnormal coronary artery. The literature shows that direct reimplantation (coronary button technique) is independent of similar survival and reoperation rates compared with the Takeuchi procedure [Hoashi 2013]. The complication and mortality of the reimplantation technique is low, and there are publications showing that long-term results are good [Naimo 2016]. Another surgical approach involves placing a saphenous vein graft between the aorta and the distal coronary artery and ligation of the proximal coronary artery ostium. In pediatric patients, a saphenous vein is not preferred, due to diameter mismatch and high risk of intimal hyperplasia and atherosclerosis in the long run [Conkbayir 2019]. In adult patients, the left internal thoracic artery can be preferred as a bypass graft to the left anterior descending artery and the saphenous vein to circumflex artery bypass, while an anostomosis that can be performed between the left internal thoracic artery and left main coronary artery can provide the most physiological flow [Ata 2019]. The Takeuchi procedure was mostly preferred in relatively younger age patients who did not have sufficient coronary length for direct implantation in our series. Direct implantation technique was the most commonly used technique in our series and applied in four cases with sufficient coronary body length. In one relatively grown-up patient with short coronary artery for reimplantation, the left internal thoracic artery to left main coronary artery bypass was preferred. The patency rates and excellent growth potential of the internal thoracic artery grafts in pediatric patients, when used for coronary artery bypass procedures, have been proven in the literature [Arnaz 2018].

Limitations: The major limitation of the study was the small size of the cohort. Another limitation is the retrospective nature of the study.

\section{CONCLUSION}

The diagnosis of ALCAPA or ARCAPA may be challenging; however, early diagnosis of the pathology in which the coronary artery originates from the pulmonary artery has critical importance. Patients should be treated before congestive heart failure and fatal complications occur. Surgical correction should be planned regardless of the symptom status, even though some of patients reach the adulthood with an increased number of collaterals. The defined surgical interventions, including the internal mammary artery to left main coronary artery anostomosis, as well as defined other techniques, such as Takeuchi and direct implantation, will provide physiologic coronary flow and longer-term survival.

In the current report, we aimed to present our modest experience on anomalous coronary arteries arising from the pulmonary artery in a context of variations and alternative surgical treatment techniques. Multicenter studies with increased cohort sizes with long-term follow-up results of applied surgical techniques are warranted in order to establish a treatment protocol for this challenging pathology.

\section{REFERENCES}

Alexi-Meskishvili V, Nasseri BA, Nordmeyer S, et al. 2011. Repair of anomalous origin of the left coronary artery from the pulmonary artery in infants and children. J Thorac Cardiovasc Surg. 142(4):868 874.

Arnaz A, Sarioglu T, Yalcinbas Y, Erek E, Turkoz R, Oktay A, Saygili A, Altun D, Sarioglu A. 2018. Coronary artery bypass grafting in children. J Card Surg. Jan;33(1):29-34.

Ata EC, Erkanlı K, Yıldız E, Türko lu H. 2019. A new surgical approach to a patient with anomalous origin of left coronary artery from pulmonary artery: A case report. Turk Gogus Kalp Damar Cerrahisi Derg. Jan 1;27(1):107-110.

Balakrishna P, Illovsky M, Al-Saghir YM, Minhas AM. 2017. Anomalous Origin of Right Coronary Artery Originating from the Pulmonary Trunk (ARCAPA): an Incidental Finding in a Patient Presenting with Chest Pain. Cureus. 9(4):e1172.

Bonnemains L, Lambert V, Moulin-Zinch A, Youssef D, Serraf A. 2010. Very early correction of anomalous left coronary artery from the pulmonary artery improves intensive care management. Arch Cardiovasc Dis. 103(11):579-84.

Ceylan Ö, Örün Arman U, Koç M, Özgür S, Do an V, Karademir S, Keskin M, Yılmaz O. 2013. Anomalous coronary artery originating from the pulmonary artery: a report of four cases. Turk Gogus Kalp Dama. 21:122-126.

Conkbayir C, Coskun U, Oztas DM, Beyaz MO, Meric M, Ugurlucan M. 2019. Coronary Arteries Arising from Single Coronary Ostium: A Case Report. Heart Surg Forum. Jun 21;22(3):E269-E270.

Conkbayir C, Oztas DM, Ugurlucan M. 2019. Right coronary artery to left carotid artery collateral in the absence of stenosis. J Card Surg. Sep;34(9):856-857.

Friedman AH, Silverman NH. 2010. Congenital anomalies of the coronary arteries. In: Anderson RH, Baker EJ, Penny D, Redington AN, Rigby ML, Wernovsky G, editors. Pediatric cardiology. 3rd ed. Philadelphia: Churchill Livingstone. p. 932-42.

Georgiev SG, Lazarov SD, Mitev ID, Latcheva AZ, Christov GA, Velkovski IG, et al. 2012. Left ventricular and mitral valve function long after repair of left anomalous coronary artery from the pulmonary artery: Recovery years after severe ischemia. World J Pediatr Congenit Heart Surg. 3:321-7.

Ghaderi F, Gholoobi A, Moeinipour A. 2014. Unique echocardiographic 
markers of anomalous origin of the left coronary artery from the pulmonary artery (ALCAPA) in the adult. Echocardiography. 31(1):E13-5.

Guenther TM, Sherazee EA, Wisneski AD, Gustafson JD, Wozniak CJ, Raff GW. 2020. Anomalous Origin of the Right Coronary Artery from the Pulmonary Artery: A Systematic Review. Ann Thorac Surg. S0003-4975(20)30352-0.

Gupta R, Marwah A, Shrivastva S. 2012. Anomalous origin of right coronary artery from pulmonary artery. Ann Pediatr Cardiol. 5(1):95-96.

Guzeltas A, Ozturk E, Tanidir IC, Kasar T, Haydin S. 2017. Evaluation of Anomalous Coronary Arteries from the Pulmonary Artery. Braz J Cardiovasc Surg. 32(1):29-37.

Hoashi T, Kagisaki K, Okuda N, Shiraishi I, Yagihara T, Ichikawa H. 2013. Indication of Takeuchi technique for patients with anomalous origin of the left coronary artery from the pulmonary artery. Circ J. 77:1202-7.

Jian-Yong Z, Ling H, Wen-hong D, Mei j, Gui-Zhen Z. 2010. Clinical features and long-term prognosis of patients with anomalous origin of the left coronary artery from the pulmonary artery. Chin Med J. 123(20):2888-94.

Koestenberger M, Nagel B, Gamillscheg A, Temmel W, Cvirn G, Beitzke A. 2007. Myocardial infarction in an adolescent: anomalous origin of the left main coronary artery from the right coronary sinus in association with combined prothrombotic defects. Pediatrics. 120:e424-7.

Kristensen T, Kofoed KF, Helqvist S, Helvind M, Sondergaard L. 2008. Anomalous origin of the left coronary artery from the pulmonary artery (ALCAPA) presenting with ventricular fibrillation in an adult: a case report. J Cardiothorac Surg. 3(38):1-5.

Li M, Wang Y, Zhu W, Zhang C, Fei H. 2020. Transthoracic echocardiography features of adult-type anomalous left coronary artery from the pulmonary artery before and after surgery: highlights from observational study in a single center of China [published online ahead of print, 2020 Apr 23]. Int J Cardiovasc Imaging. 10.1007/s10554-020-01857-x.

Matherne GP, Lim S. 2008. Congenital anomalies of the coronary vessels and the aortic root In: Allen HD, Driscoll DJ, Shaddy RE, Feltes TF, editors. Moss and Adams' heart disease in infants, children, and adolescents: including the fetus and young adults. 7th ed. Baltimore: Lippincott Williams \& Wilkins. p. 703-25.
Naimo PS, Fricke TA, d'Udekem Y, Cochrane AD, Bullock A, Robertson T, Brizard CP, Konstantinov IE. 2016. Surgical intervention for anomalous origin of left coronary artery from the pulmonary artery in children: A long-term follow-up. Ann Thorac Surg. 101:1842-8.

Pandey NN, Sinha M, Sharma A, Rajagopal R, Bhambri K, Kumar S. 2019. Anomalies of coronary artery origin: Evaluation on multidetector CT angiography. Clin Imaging. 57:87-98.

Parasramka S, Dufresne A. 2011. Anomalous origin of right coronary artery from pulmonary artery presenting as chest pain in a young man. J Cardiol Cases. 5(1):e20-e22.

Sato Y, Sakaguchi R, Innami Y, Katori N, Morisaki H. 2013. Perioperative management of a patient with anomalous origin of the left coronary artery from the pulmonary artery. Masui. 62(10):1191-3.

Su JT, Krishnamurthy R, Chung T, Vick GW 3rd, Kovalchin JP. 2007. Anomalous right coronary artery from the pulmonary artery: noninvasive diagnosis and serial evaluation. J Cardiovasc Magn Reson. 9(1):57-61.

Tsutsumi K. 2014. Surgical repair of anomalous connection of the left coronary artery. SAGE Open Med Case Rep. 2: 2050313X14550118.

Ugurlucan M, Yildiz Y, Ulukan MO, Oztas DM, Beyaz MO, Canata E, Coban S, Unal O, Erkanli K, Turkoglu H. 2020. A surgical technique for ascending aorta, aortic arch and descending aorta replacement without cross-clamp, circulatory arrest or hypothermia. Cardiol Young. Jan;30(1):24-27.

Williams IA, Gersony WM, Hellenbrand WE. 2006. Anomalous right coronary artery arising from the pulmonary artery: a report of 7 cases and a review of the literature. Am Heart J. 152(5):1004.e9 1004.e1.004E17.

Yakut K, Tokel NK, Ozkan M, Varan B, Erdogan I, Aslamaci MS. 2019. Diagnosis and treatment of abnormal left coronary artery originating from the pulmonary artery: A single center experience. Anatol J Cardiol. 22(6):325-331.

Zheng JY, Han L, Ding WH, Jin M, Zhang GZ, Xiao YY, Luo Y, Cheng P, Meng X, Zhao QM. 2010. Clinical features and long-term prognosis of patients with anomalous origin of the left coronary artery from the pulmonary artery. Chin Med J (Engl). 123(20):2888-2894. 